\title{
A importância da temática de História e Cultura Africana e Afro-brasileira nas escolas
}

\author{
The importance of thematic of History and the African Culture and \\ Afro-Brazilian in the schools
}

\author{
Juliana Souza Krauss* \\ Julio César da Rosa*
}

\begin{abstract}
RESUMO
ABSTRACT

O presente artigo visa discutir a importância e This paper discusses the importance and indispensabilidade da Lei 10.639/2003 dando indispensability of Law 10639/2003 emênfase ao papel desempenhado pelas popula- phasizing the key role played by people of ções de origem africana na construção da his- African descent in the construction of Brazil's tória do Brasil, bem como as circunstâncias que history and the circumstances that led to the levaram a criação da referida Lei. Também são creation of the aforementioned Act are also analisados como se estabelecem as relações in- examined as are established ethnic relations terétnicas no contexto escolar, as manifesta- in the school context, the manifestations of ções de discriminação no ambiente escolar co- discrimination in the school environment metidas tanto por alunos(as), professores(as), committed by both the students, teachers, diretores(as), etc; a maneira como os docentes directors, etc., and the way teachers and e a escola devem lidar com o racismo e com o schools should deal with racism and prejudice, preconceito, trata brevemente sobre a questão it briefly on the issue of education maroon, and da educação quilombola; e a aplicação da Lei the application of law by both the teacher and tanto por parte do educador como da escola, the school, showing routes to be followed by apontando caminhos a serem trilhados por educators through the reframing of the parte dos educadores através da resignificação concepts of some words used in everyday dos conceitos de algumas palavras utilizadas school life.
\end{abstract}

no cotidiano escolar.

PALAVRAS-CHAVE: Relações interétnicas; Edu- KEYWORDS: Ethnic relations; Education; Law cação; Lei 10.639/03; Discriminação; Prática 10.639/o3; Discrimination; Teaching practice. docente.

A publicação da Lei $n^{0}$ 10.639/2003 se da num contexto educacional abrangente, determinado pelas transformações oriundas da promulgação da Lei de Diretrizes e Bases no 9.394, de 1996, na qual se afirmam modificações educacionais importantes, como a flexibilidade curricular, a conscientização e o valor da inclusão e da diversidade na educação, reafirmando também a autonomia do docente. Sendo o resultado dessa junção, a criação de vários

\footnotetext{
Mestranda em História pela Universidade do Estado de Santa Catarina (UDESC) / Brasil.

** Mestrando em História e Bolsista do Núcleo de Estudos Afro-Brasileiros (NEAB) da Universidade do Estado de Santa Catarina (UDESC) / Brasil.
} 
programas municipais e regionais que destacam a temática das relações étnicoraciais na escola e nos conteúdos ministrados, tanto nas políticas públicas educacionais quanto na acadêmica.

$\mathrm{O}$ advento da Lei ocorre graças a um intenso debate social ampliado pela mídia, que expressava o impacto inicial da implantação do programa de ações afirmativas em algumas universidades brasileiras. As "Diretrizes" exibem dimensões normativas relativamente flexíveis, sugerindo conteúdos, valores e referências para a prática docente, de acordo com o pressuposto da formação e da educação para a valorização da diversidade cultural.

O conteúdo e as transformações dela decorrentes geram uma tensão entre a extensão dos direitos de cidadania no país e a crescente compreensão do imprescindível enfrentamento do racismo, na suas várias formas de manifestação e nos diversos âmbitos da vida social, sobretudo no espaço escolar. A Lei contempla à sua maneira, o embate da antiga crítica ao ensino da história centrado nas narrativas etnocêntricas, na qual a história e cultura afrobrasileira aparece em via de regra -quando aparece- de forma estereotipada. A proposta tem como objetivo discutir e refletir, no cotidiano, temas como a maneira na qual são estabelecidas as relações interétnicas na nossa sociedade (PEREIRA, 2008: 22).

Sendo que nessas relações, na maioria dos casos os não negros vêem nos afrodescendentes sinônimo de inferioridade, estigmatizando também a sua cultura, entendida como de menor valor em relação àquela trazida pelo mundo euro-ocidental. Infelizmente essas manifestações preconceituosas ocorrem também no espaço escolar sendo praticadas tanto por crianças, como por profissionais da educação, como nos afirma Cavalleiro:

\begin{abstract}
Localiza-se nos programas escolares, pelas falas dos profissionais da educação, a necessidade de fortalecimento da identidade racial. Isso pode se depreender no que se refere à diversidade. Há um esforço para melhorar atitudes, valores, comportamento e aceitação do "outro" que é discriminado. Entretanto, o dia-a-dia das escolas não indica a elaboração/realização de novas práticas educativas. Observa-se que ocorrem, no cotidiano escolar, a disseminação de ideologias racistas, bem como a de práticas discriminatórias dirigidas às crianças negras, tanto por profissionais da educação quanto pelos colegas (CAVALLEIRO, 2005: 98).
\end{abstract}

Tal situação se desenrola, sobretudo nas aulas de História do Brasil Colonial, na qual os "negros" são retratados apenas como escravos, obedientes, coitados e suas características físicas são menosprezadas. Essa visão 
preconceituosa está presente em boa parte dos materiais pedagógicos utilizados pelos(as) professores(as). Esses materiais não mencionam as relações culturais e sociais dos africanos e seus descendentes, sendo que estes aparecem apenas realizando trabalho compulsório. As diferentes formas de resistência à escravidão raramente são mencionadas e a questão da abolição é tratada como uma dádiva da elite branca progressista que tencionava desenvolver o capitalismo no Brasil, sendo portanto contra a escravidão.

[...] O preconceito incutido na cabeça do professor e sua incapacidade em lidar profissionalmente com a diversidade, somando-se ao conteúdo preconceituoso dos livros e materiais didáticos e às relações preconceituosas entre os alunos de diferente ascendências étnicoraciais, sociais e outras, desestimulam o aluno negro e prejudicam seu aprendizado (MUNANGA Apud CAVALLEIRO, 2005: 70).

No que diz respeito ao continente africano é ainda pior. Os livros didáticos tradicionais se referem à África utilizando termos discriminatórios. $\mathrm{O}$ conhecimento sobre os aspectos econômicos, políticos e culturais é quase inexistente, como se a África passasse a existir depois da escravidão. Segundo Pereira:

O que chamamos de cultura de valor na Europa, na África são costumes exóticos. O que os europeus chamam de filosofia e religião toma os nomes de crendice e superstição na África. As lutas de classes são reduzidas a lutas tribais. No estudo da formação de nacionalidade, a participação dos africanos e de seus descendentes é escamoteada e relegada a uma "contribuição ao folclore, à culinária e misticismo". Conhecemos a África das tribos, do Simbá, dos safaris, da Aids, da fome e das guerras. O continente africano permanece para a maioria dos brasileiros reduzida a uma imagem simplificada por quatro t: tribo, tambor, terreiro, tarzan (PEREIRA Apud SILVA, 2009: 5).

As "Diretrizes" tem como finalidade recomendar determinados conteúdos programáticos e suas formas de abordagens, utilizando alguns interlocutores considerados mais autorizados para a implementação de propostas dessa natureza, como o Movimento Negro, por exemplo. Sendo que essa legitimidade dada ao movimento ocorre pelo fato que o mesmo durante muito tempo tomou para si a responsabilidade sobre a educação dos negros:

\footnotetext{
Movimentos sociais negros se concentravam na luta pela educação do negro, a imprensa negra - nascida dessas organizações tornou-se difusora de ideias que relacionava educação e ascensão social. Pinto (1993) dedica uma seção específica à análise do significado da educação para o negro. Segundo esta autora, depois da abolição, somente encontramos referências à escolarização dos negros, a partir da década de 1930, isso nos permite afirmar que, por iniciativa do Movimento Negro, foram fundadas as primeiras escolas voltadas especificamente para a educação do negro. [...] o preconceito e a discriminação que ocorrem dentro da própria instituição escolar,
} 


\begin{abstract}
dificultando o acesso da criança negra à escola, explicam, pelo menos em parte, as iniciativas da comunidade negra em criar suas próprias escolas. O fato é que as próprias organizações negras chamaram para si a responsabilidade de educar as crianças. O Movimento Negro, neste momento inicial, trabalhava no sentido de conscientizar a população negra da importância do estudo para integração e ascensão social (PINTO Apud MARINHO Jr., 2008: 3).
\end{abstract}

Tal discurso se modificará a partir da década de 1940 com a Convenção do Negro Brasileiro, realizada em São Paulo e no Rio de Janeiro, que tinha como objetivo valorizar a memória dos negros brasileiros e sua cultura, no intuito de positivar a imagem do negro, salientando sua importância na constituição da identidade nacional. Como foi dito na citação acima, a valorização da educação foi uma das várias técnicas utilizadas pelos negros para a ascensão social, a escola foi definida socialmente como um veículo para superar a exclusão sócioracial à que estavam submetidos; sendo que uma das bandeiras dos militantes negros na primeira metade do século $\mathrm{XX}$, enquanto não houvesse ensino gratuito em todos os graus, os estudantes negros deveriam ser admitidos como pensionistas do Estado, em todos os estabelecimentos oficiais, militares e particulares tanto no ensino secundário quanto no ensino superior. Em meados da década de 1950, passa-se a discussão da importância em se investir na escola pública para todos, sob a tutela do Estado, segundo Azevedo:

A escola pública, cujas as portas, por ser escola gratuita, se franqueiam a todos, sem distinção de classes, de situações, de raças e de crenças, é, por definição, contrária e a única que está em condições de se subtrair a imposição de qualquer pensamento sectário, político ou religioso (AZEVEDO Apud DIAS, 2005: 52).

Outro importante passo dado em direção a uma educação livre de discriminações raciais foi a promulgação da Lei 4.024/61 que frisa que a educação nacional é inspirada nos princípios de liberdade e nos ideais de solidariedade humana, sendo sua finalidade: a condenação de qualquer tratamento desigual por convicção filosófica, religiosa ou política e qualquer manifestação de preconceito de classe ou raça. Infelizmente a questão racial foi tratada na Lei de Diretrizes e Bases da Educação Nacional (LDB) de 1961 apenas de forma secundária, figurando mais enquanto recurso discursivo, os educadores daquele período reconheceram a questão racial como um dos fatores de diferenciação no processo escolarização, mas essa discussão não foi centralizada na defesa de uma escola para todos, neste aspecto esses educadores na época taxado de "modernos" pouco se diferenciavam dos educadores 
Juliana Souza Krauss e Julio César da Rosa

A importância da temática de História e Cultura Africana e Afro-brasileira nas escolas

conservadores.

As duas LDBs que seguiram a de 1961, a Lei 5.540/68 e 5.692/71, foram importantes na organização do ensino brasileiro, além de manterem a condenação à discriminação racial; já na LDB de 1988 resultado de amplas discussões dos educadores progressistas, a questão racial desaparece do texto.

A Constituição de 1988 serviu de base para a criação da Lei 9.394/96, noaqual o ensino da História do Brasil levará em conta as contribuições de diferentes etnias e culturas na formação do povo brasileiro, especialmente as de origem: africana, indígena e europeia.

\begin{abstract}
A década de 90, evidentemente, apresenta uma trajetória de melhoria nos indicadores educacionais, [...], os avanços são, por vezes, tímidos e, em geral, não interferem de forma significativa na estrutura de discriminação racial e de gênero. Assim, apesar dos avanços nos indicadores quantitativos, as desigualdades raciais e de gênero continuam significativas e sinais relevantes de transformação nos padrões da discriminação ainda não são detectáveis com nitidez. $\mathrm{O}$ desafio estrutural de uma reforma educacional implica, portanto, a construção de bases efetivas para implementação de um ensino norteado pela qualidade e equidade, que enfrente os contornos da desigualdade racial que atravessam, de forma contundente, o sistema educacional brasileiro (HENRIQUES Apud DIAS, 2005: 60).
\end{abstract}

Sucintamente foram estes os caminhos percorridos em termos de legislação até chegarmos a Lei 10.639/03. Mas, é importante ressaltar que alguns aspectos presentes nessa Lei, como a inclusão da história do continente africano e afro-brasileira, são reivindicações dos Movimentos Sociais Negros e dos intelectuais negros, e datam pelo menos de meados da década de 1940, sendo portanto conquistas que nos chegam tardiamente, como consequência da perseverança desses(as) militantes e intelectuais.

[...] No campo das políticas públicas educacionais, contamos com dois marcos legais importantes para inclusão da população negra e, principalmente, a sua permanência no sistema educacional brasileiro: o Artigo 26 da Lei de Diretrizes e Bases da Educação Nacional (LDB), que estabelece a obrigatoriedade do ensino de História e Cultura AfroBrasileira na Educação Básica; e a Resolução CNE nº 01/2004, que instituiu as Diretrizes Curriculares Nacionais para a Educação das Relações Étnico-Raciais e para o Ensino de História e Cultura AfroBrasileira e Africana. (BOTELHO, 2007: 34).

Nas "Diretrizes", são sugeridas alternativas para a prática docente, pontuando a necessidade da interdisciplinariedade e de uma reformulação das concepções da história e, portanto, de uma recomposição dos currículos (PEREIRA, 2008: 24).

No referente à cultura, elas tendem para a afirmação da existência de uma 
cultura africana e negra que se contrapõem ao padrão estético e cultural branco, sobretudo europeu. O Brasil ainda insiste no "imaginário étnico-racial” que desprestigia as raízes asiáticas, africanas e indígenas na nossa cultura (PCNs Apud ABREU e MATTOS, 2008: 13). Apesar das "Diretrizes" defenderem a existência de diversas culturas como a africana, europeia, indígena e asiática, não é pensado as identidades culturais enquanto construções conflituosas datadas historicamente. Os intercâmbios culturais e a hibridização das culturas não são consideradas como meio de trabalhar com as culturas.

Elas trazem para o espaço escolar, pela primeira vez, discussão das relações étnico-raciais no Brasil e o combate ao racismo, inúmeras vezes silenciado ou desqualificado pelas avaliações que o Brasil é uma democracia racial. Segundo Abreu e Mattos:

[...] O parecer aprovado pelas "Diretrizes" possui um tom claramente mais político que o dos PCNs, já que diretamente relacionado à questão do combate ao racismo. De maneira inequívoca, educadores diretamente ligados aos movimentos negros respondem agora pela redação do documento. Nesse sentido, o parecer se propõe "oferecer uma resposta, entre outras, na área da educação, à demanda da população afro-descendente, no sentido de políticas de ação afirmativa, isto é, de políticas de reparações, e de reconhecimento e valorização de sua história, cultura, identidade" (ABREU e MATTOS, 2008: 9).

É necessário que o educador tenha em mente que o ensino da história está relacionado com os processos de manipulação da memória e as várias tentativas de reconfiguração da identidade em seus diversos matizes. Pois, a questão racial brasileira na sua historicidade, está marcada, na contemporaneidade, pela emergência -divergente e contraditória- de perfis identitários do Brasil e pela recente problematização na configuração da sociedade brasileira como democrática, plural, diversa, igualitária e inclusiva.

É imprescindível que o profissional da história possua um conhecimento mais substancial sobre a história do Brasil e suas conflituosas relações de poder, e principalmente compreenda o racismo histórico brasileiro, tendo a sensibilidade através de suas ações, de problematizar as situações vivenciadas no cotidiano escolar. Esse exercício implica que o(a) professor(a) renove seus conhecimentos necessários na sua formação acadêmica, sendo capaz de avaliálos na sua prática docente, constituindo um universo de significados e reflexões que possibilitem nas diversas situações da ação pedagógica, compreender, problematizar, propor atividades e assumir posturas fundamentais com seus 
alunos, permitindo- lhes um melhor entendimento sobre o valor da pluralidade cultural e da convivência pacífica na sociedade -apesar de não estar inseto de conflitos, e sim constituindo interações e convivências não-racistas (PEREIRA, 2008: 26).

Mesmo a Lei prevendo a obrigatoriedade de alguns conteúdos no ensino de história, ela irá impactar não somente a organização, como também a seleção e elenco de temáticas. Uma das principais consequências de sua implementação pela escola é a mudança de narrativas nas aulas de história, em que o Brasil afro-brasileiro, bem como sua ancestralidade histórica, passa a ser compreendido de maneira positivada -o mesmo poderá ser dito sobre história da África. Portanto, uma educação das relações étnicas dentro desse contexto é possivelmente menos um conteúdo e mais o alicerce da ação educativa, enraizando-se por todo o currículo.

Atualmente, as dimensões étnicas do ensino da história desafiam os(as) professores(as) a constituírem uma formação profissional e uma prática autoreflexiva e atenta à complexidade dos processos históricos; exercendo através da análise do debate historiográfico referentes à questão da escravidão e do racismo, ultrapassando as abordagens pautadas em visões etnocêntricas e superficiais sobre os processos históricos (PEREIRA, 2008: 28).

A inclusão desta temática fará com que os alunos(as) e professores(as) reflitam sobre a presença dos afro-brasileiros dentro das escolas e na sociedade brasileira, presença essa muitas vezes desconsiderada. Na agenda de implementação da Lei nas escolas, existem inúmeras questões e ações a serem revistas. Como a Lei existe e deve ser cumprida em todos os níveis da educação, as primeiras ações a serem tomadas pela escola são a capacitação do corpo docente e a aquisição de material adequado para o ensino da história e cultura afro-brasileira e africana.

Outro ponto importante tratado pela Lei é a questão da educação quilombola. Primeiramente é necessário conceituarmos o que é uma Remanescente de Quilombos ou Quilombo Contemporâneo: são comunidades negras rurais habitadas por descendentes de escravos, no qual são mantidos laços de parentesco e as pessoas sobrevivem geralmente de cultura de subsistência em terras compradas, doadas ou ocupadas há muitas gerações pelo grupo. Essas comunidades passaram a ser percebidas pelo governo a partir da 
Constituição Federal de 1988, no Art. 68 que trata dos Atos das Disposições Constitucionais Transitórias que garantiu a propriedade dessas terras aos seus moradores. Amparados pela Lei os quilombolas lutam pela escritura definitiva de suas terras. Atualmente buscam superar prática da cultura de subsistência, acreditam na possibilidade de sobreviverem cultuando as tradições do passado e o legado dos ancestrais, sempre usando estratégias de desenvolvimento sustentável, como garantia de uma vida digna.

O Movimento Negro classifica os Quilombos, tanto os do período escravista como os contemporâneos, como "pedaços da África no Brasil", pelo fato da organização dos mesmos se assemelhar com diversas sociedades africanas:

Na cultura africana tradicional, todos os elementos da vida estão interligados. A religião, a política, a família, o território, a moradia somente têm sua função plenamente cumprida se estão intrinsecamente relacionados, e sua existência formal e estrutural está profundamente conectada com a estrutura dos demais itens da vida. Sendo assim, a tradição oral de transmissão do conhecimento, típica das sociedades africanas, só tem sentido com a proximidade do interlocutor, já que, para o africano, a comunicação tem que ser viva, dinâmica, e essa energia viva não é transmitida por meio das letras (Nascimento, 2002). A família, por sua vez, tem nas tradições de linhagem e parentesco um componente importante de estruturação familiar, de transmissão de conhecimento para as gerações seguintes. Isso cria a necessidade de proximidade das famílias, com a construção das casas dos filhos casados em torno das moradias dos mais velhos, pais e avós, o que estabelece, por si só, a manutenção da tradição, o aprendizado dos mais novos pela experiência dos mais velhos e as relações de vizinhança. Sendo assim, o princípio organizacional do espaço quilombola, ao constituir na atualidade um local de resistência e da vivência dos africanos que aqui chegaram, cumpre um papel fundamental na manutenção das formas de produção social, da cosmovisão africana e na sobrevivência desta população como comunidade negra constituída, com consciência de grupo e de origem comum. Esta ocupação territorial pelas famílias obedece a um sistema de relações em que a casa principal do grupo é a residência dos pais, que tem ligações diretas com a residência dos filhos; além destas, há uma terceira esfera de relações com as áreas de plantio e criação, com cada unidade de moradia tendo suas próprias hortas e pomares, embora de usufruto de todos os membros do núcleo familiar, obedecendo a um sistema de organização encontrado também em regiões de Guiné-Bissau, Angola e Moçambique até os dias atuais. As relações sociais assim determinadas levam a uma autonomia das famílias agrupadas, com suas áreas de criação e plantio para subsistência contidas na área familiar. Ao mesmo tempo, identifica-se o planejamento conjunto dos elementos de infra-estrutura da comunidade, como fontes de água, as antigas matas e áreas de pesca, fontes de alimento e manutenção do quilombo, em um sistema de autonomia e interdependência (PARÉ; OLIVEIRA; VELLOSO, 2007: 220-221).

O estudo da história dos Quilombos Contemporâneos é extremamente 
importante para a afirmação identitária do povo brasileiro e a inclusão no Currículo da Educação Básica é primordial para a formação da nacionalidade. Muitas iniciativas foram tomadas até a inclusão especifica dessa Temática nos Currículos Educacionais, a Lei 9.394/96 no Art. 26 trata sobre a produção e distribuição de materiais didáticos que abordam a história e a cultura das comunidades quilombolas.

O Ministério da Educação tem desenvolvido alguns projetos neste sentido, como apoio financeiro aos municípios que possuem os remanescentes quilombolas, constrói e equipa escolas nessas áreas, através do Fundo de Fortalecimento da Escola (FUNDESCOLA), a metodologia utilizada segui o princípio de ensino da Escola Ativa. As salas de aula projetadas pelo FUNDESCOLA obedecem aos padrões mínimos de funcionamento e contam com a construção da "Casa do Professor", por se tratarem de áreas de difícil acesso aos mesmos, a contratação dos professores é de responsabilidade dos municípios. Essas iniciativas são extremamente importantes, mas ainda são incipientes como nos descreve Botelho:

[...] No que se refere à educação em prol da valorização da população negra brasileira, ainda se verificam inúmeras resistências. Precisamos, pois, identificar políticas públicas que atem às necessidades desse contingente populacional, que não se vê representado e valorizado nas experiências educacionais. No caso específico da população remanescente de quilombos, precisamos avançar muito mais, posto que, entre os afro-brasileiros, esse grupo soma os maiores índices de exclusão educacional. (BOTELHO, 2007: 35).

É importante que o(a) educador(a) tenha consciência que a estrutura organizacional dessas comunidades difere em muitos aspectos da nossa sociedade, tornando necessário uma abordagem metodológica que vai ao encontro das necessidades dessas comunidades:

A grande diferença que se deve destacar entre a transmissão do saber nas comunidades negras rurais e nas escolas é que, no primeiro caso, o processo, fruto da socialização, desenvolve-se de forma natural e não formal e, no segundo, o saber nem sempre está referenciado na experiência do aluno. (MOURA, 2007: 6).

A escola tem por obrigação transmitir a história dessas comunidades, bem como sua atual situação. A difusão dos saberes dessas populações entre todas as crianças brasileiras é extremamente importante, pois permite a compreensão e a afirmação da nossa identidade pluricultural e multiétnica, no qual deve basear-se "a defesa consciente de valores da cidadania" (Moura, 2007: 5).

Segundo Pereira (2008: 30) são grandes os desafios a serem enfrentados 
no ensino da história dentro da perspectiva da Lei $\mathrm{n}^{0}$ 10.639/2003. Esses desafios correspondem, evidentemente, à postura que os(as) professores(as) adotam diante da Lei, bem como o valor atribuído por diferentes funcionários da escola quanto à questão do racismo e do estudo da cultura afro-brasileira e africana. Sendo que se estabeleceu, como não poderia deixar de ser, uma realidade heterogênea no qual é possível encontrar desde projetos muitos densos e fundamentados, até a negação da relevância da Lei para o ensino da história, como nos descreve Munanga:

\begin{abstract}
Certas escolas, através de seus educadores e diretores, dizem que não se deve ensinar, nem discutir o assunto. Falam que aqui não tem negro, não tem branco, todo mundo é mestiço, etc. Nós precisamos vencer esta resistência. Não basta fazer a lei. Tem que sancionar. Tem que avaliar o uso e, se necessário punir. [...] alguns municípios têm alguma coisa em andamento, mas em outros há uma resistência total. Isto precisa ser revertido (MUNANGA apud SILVA, 2009: 18).
\end{abstract}

O objetivo da Lei 10.639/o3 não é substituir uma educação eurocêntrica por outra afrocêntrica, mas sim valorizar os aspectos culturais africanos e afrobrasileiros que por muitos anos foram silenciados e discriminados na educação nacional, portanto é papel fundamental do docente educar para a diversidade. Ou seja:

O problema não é afirmar um pólo e negar outro, mas sim termos uma visão dialética da relação entre igualdade e diferença. Hoje em dia não se pode falar em igualdade sem incluir a questão da diversidade, nem se pode abordar a questão da diferença dissociada da questão da igualdade. [...] não se deve opor igualdade à diferença. De fato, a igualdade não está oposta à diferença e sim à desigualdade. Diferença não se opõe à igualdade e sim à padronização, à produção em série, a tudo ‘o mesmo', à 'mesmice' (CANDAU Apud OLIVEIRA, 2007: 11).

Não é suficiente introduzir os conteúdos de história e cultura afrobrasileira ou africana para superar o eurocentrismo nas abordagens dos processos históricos. O desafio é promover um ensino-aprendizagem na qual a história da Ásia, por exemplo, não seja dicotomizada, nem contraposta, muito menos idealizada, mas que, sobretudo, possa ser compreendida na sua dinâmica e circularidade, com os embates do passado e do presente, na perspectiva da exigência de uma abordagem histórica substantiva.

É importante atentarmos para o perigo de "folclorizar" a história e a cultura afro-brasileira, despolitizando e reduzindo a um mero elemento de constituição de uma suposta identidade nacional. Sendo indispensável que o estudo das diversas culturas brasileiras, possa ser vislumbrado na sua relação com os aparatos éticos, políticos e históricos que as constituem. 
Dentro da perspectiva multicultural existem conflitos com as quais a escola se defronta, como a diversidade e a homogeneidade. É preciso pensar na importância de se iniciar o debate entre educação e perspectiva multicultural, para que os(as) professores(as) possam assumir a responsabilidade de desconstruir atitudes e posturas discriminatórias e preconceituosas do pensamento hegemônico, como também a desestruturação do currículo, dentro de uma perspectiva europeia, branca e dominante. $\mathrm{O}$ ambiente escolar é privilegiado, tanto pode reproduzir as práticas racistas, quanto dar outro significado a seus efeitos, fazendo com que o racismo se eternize ou não, em relação à questão da aprendizagem (SILVA, 2009: 7).

Aceitar como naturalmente existente as identidades negras e a cultura afro-brasileira, é desconsiderar a dimensão das lutas travadas em volta da constituição de identidades -indígena, regional, popular, etc.- no decorrer da história do Brasil. É necessário atentarmos para a importância de pensarmos a história dos conceitos da cultura afro-brasileira e das identidades negras.

Será necessário discutir na sala de aula conceitos essenciais para compreender as relações sociais no Brasil, como o termo "negro", "raça", "democracia racial", "preconceito racial”, "negritude", "etnia" e "identidade étnica”, conceitos esses que devem ser abordados percebendo-se que ao longo dos séculos sofreram transformações epistêmicas, e que na contemporaneidade não dão conta de discutir as relações sociais (interétnicas) ou se tornaram anacrônicos para tais interpretações.

Diante desta constatação é necessário que a abordagem da história da África e cultura dos afro-brasileiros seja, num primeiro momento, a de apreensão por partes dos alunos desses conceitos, para compreensão da especificidade da história de quase 400 anos de escravidão, e como ainda esses conceitos se refletem atualmente.

Começaremos analisando como o termo "negro", que no período da escravidão tinha um significado pejorativo, determinista e reducionista, e como ainda na contemporaneidade é carregado de preconceitos e valoração. Operando no sentido de desqualificar uma categoria de indivíduos, determinando que todos os africanos e/ou "negros” em África eram iguais, consequentemente desqualificando suas tradições, seus valores, suas culturas, homogeneizando um continente diverso a um único termo o ser "negro". Essa conotação da palavra negro associada a uma cultura não ocidental se deu por conta de fatores econômicos e expansionistas, à redução de homens e mulheres antes de serem negros e africanos eram bantus, gegê, malês, yorubás, benguela, 
nagôs reduzidos agora a "combustível biológico" como cita Petronilha:

A colonização sustentada pelo escravismo, nos limites da situação acima tracejada, criou "uma categoria de seres humanos" e os batizou genericamente e pejorativamente de negros. Assim denominados, os africanos, membros de etnias e de povos oriundos de cultura diversas, foram reduzidos ao estado de combustível biológico (SILVA, 1997: 43).

Essa relação de poder de uma cultura em detrimento de outra, reforça a ideia de superioridade justificada através de um projeto civilizatório que acabou transformando o diferente, não só biologicamente, mas culturalmente em um ser inferior. O problema gerado em torno do termo negro não se resume somente à problemática da escravidão. A utilização desse conceito quando se refere à questão da identidade, muitas vezes torna-se problemático:

Ser negro no Brasil não se limita às características físicas. Trata-se,
também, de uma escolha política. [...] É importante tomar
conhecimento da complexidade que envolve o processo de construção
de identidade negra em nosso país. Processo esse marcado por uma
sociedade que, para discriminar os negros, utiliza-se tanto da
desvalorização da cultura de matriz africana como dos aspectos físicos
herdados pelos descendentes de africanos. Nesse processo complexo, é
possível, no Brasil, que algumas pessoas de tez clara e traços físicos
europeus, em virtude de o pai ou a mãe ser negro(a) se designem
negros; que outros, com traços físicos africanos, se digam brancos.
(PCNs Apud ABREU e MATTOS, 2008: 10).

A construção de outros conceitos e suas significações e re-significações formaram um conjunto de pré-conceitos que legitimaram as injustiças cometidas com os povos africanos e posteriormente com seus descendentes. Segundo Munanga (2003) "a maioria dos conceitos, tem seu campo semântico e uma dimensão temporal e espacial” o próprio dicionário traz a definição de negro como: "sombrio", "lúgubre”, "triste”, "infeliz”, etc. Como enfatiza Paulino Cardoso, o termo negro constitui uma noção problemática na medida em que tende a naturalizar uma visão racializada do mundo (CARDOSO, 2005: 173).

A visão racializada dos seres humanos tem origem nas teorias raciais do século XIX, a crença na classificação de grupos sociais hierárquicos divididos em raças estanques, produziu, exclusão e genocídio entre os seres humano. As "raças sociais" (MUNANGA, 2003: 6) deram origem a fenômenos como racismos, discriminação racial, xenofobia, preconceitos etc. A inexistência de raças humanas, comprovada por ciências como a biologia, genética, bioquímica, é um conceito inoperante cientificamente, o mesmo não da conta de explicar a diversidade humana para classificá-la em raças. Mesmo assim a sua invalidade 
cientifica não o baniu do mundo social. Sua funcionalidade opera no imaginário coletivo, naturalizando as injustiças sociais, legitimando as relações de poder e dominação existente no mundo contemporâneo.

Apesar de toda a violência do racismo e da desigualdade racial presente na sociedade brasileira, construiu-se ideologicamente um discurso que prega a existência da harmonia racial entre brancos e negros, desviando o olhar da população e do Estado brasileiro das crueldades cometidas contra os africanos e afrodescendentes escravizados no Brasil, impedindo-os de agirem de forma incisiva e eficaz contra as manifestações racistas. Esse discurso é chamado de democracia racial.

A democracia racial definiu o Brasil como um país livre de impedimentos institucionais e legais para a igualdade racial, e isento de preconceito e discriminação raciais informais, no qual a nação oferece oportunidades iguais para todos os cidadãos em todas as áreas da vida pública independente da cor da sua pele. Esse conceito recebeu uma interpretação mais coerente e concreta na década de 1930 através das obras de Gilberto Freyre, mas suas raízes se remetem ao século XIX.

Esta ideologia serviu durante o regime escravocrata para amenizar a consciência dos senhores de escravos e aplacar o pânico de represarias por parte dos escravos e ex-escravos, alegando que a escravidão foi branda no Brasil se comparada com outros países, além de fazer frente aos abolicionistas nacionais e estrangeiros que criticavam duramente a elite brasileira pelo fato de ter sido o último país independente do continente americano a abolir a escravidão. Após ser proclamada a abolição esta ideia serviu para a elite branca manter os afrodescendentes à margem da sociedade como nos afirma Andrews:

[...] Estava claro para todos que os negros continuavam a ocupar uma posição rebaixada e subordinada na sociedade brasileira. Mas proclamando que, mesmo durante a escravidão, o Brasil se movimentou rumo à igualdade racial, e com a abolição em 1888 a alcançou, a doutrina da democracia racial isentava a política do Estado ou o racismo informal de qualquer responsabilidade adicional pela situação da população negra, e até mesmo colocou a responsabilidade diretamente nos ombros dos próprios afrobrasileiros. Se os negros fracassaram em sua ascensão na sociedade brasileira, evidentemente isso foi por sua própria culpa, pois essa sociedade não reprimiu nem obstruiu de modo algum o seu progresso. A realidade continuada da pobreza e marginalização dos negros não era vista como uma refutação da ideia de democracia racial, mas sim como uma confirmação da preguiça, ignorância, estupidez, incapacidade, etc., o que impedia os negros de aproveitar as oportunidades a eles oferecidas pela sociedade brasileira - em suma, um restabelecimento 
A democracia racial se mostrou para a população negra e parda um mito ideológico, ou seja, uma narrativa construída intencionalmente para escamotear o real produzindo o ilusório e negando a história para transformá-la em "natureza'. Souza define um mito como um produto econômico-políticoideológico que constitui "um conjunto de representações que expressa e oculta uma ordem de produção de bens de dominação e doutrinação" (SOUZA Apud GOMES, 2005: 57).

O Movimento Negro tem desempenhado um papel social importante na desmistificação do mito da democracia racial no Brasil, em conjunto com pesquisadores(as) negros(as) e brancos(as) que assumem uma postura contra o racismo. As estatísticas oficiais, pesquisas, denúncias e as reivindicações dos Movimentos Negros revelam que nossa sociedade ainda "não se democratizou nas suas relações sociais e raciais" (MOURA Apud GOMES, 2005: 59).

A contestação da democracia racial por parte dos afrodescendentes, sobretudo pelo Movimento Negro, levou a admissão da existência do preconceito racial em nosso país. O preconceito se constitui num julgamento prévio e negativo dos membros de um grupo religioso, étnico-racial, ou de pessoas que possuem outro papel social significativo. A principal característica desse julgamento antecipado é a inflexibilidade, pois inclina-se a se perpetuar sem levar em consideração os fatos que o contestam, por se tratarem de conceitos ou opiniões pré-formados superficialmente sem análise ou conhecimento dos fatos. No preconceito está incluso a relação entre indivíduos e grupos humanos, além de compreender a concepção que uma pessoa tem de si mesma e do outro.

Enquanto atitude o preconceito não é inato e sim construído socialmente, portanto nenhuma criança nasce preconceituosa, ela aprende a ser. Todos nós socialmente cumprimos um percurso que tem início na família, vizinhança, círculos de amizade, igreja, escola que se estende até nos inserirmos em instituições como profissionais ou enquanto atuantes em movimentos políticos e sociais e comunidades; devemos levar em consideração que os primeiros julgamentos raciais que as crianças apresentam são consequências do seu contato com o mundo adulto; as manifestações raciais de caráter pejorativo vão se acentuando na medida em que a criança convive num ambiente que 
constantemente deprecia negros, judeus, mulheres, índios, idosos, pessoas de baixa renda e homossexuais.

Uma das formas mais comuns de manifestação do preconceito é o preconceito racial. Segundo Nogueira o preconceito racial se manifesta de duas maneiras:

\begin{abstract}
Considera-se como preconceito racial uma disposição (ou atitude) desfavorável, culturalmente condicionada, em relação aos membros de uma população, aos quais se têm como estigmatizados, seja devido à aparência, seja devido a toda ou parte da ascendência étnica que se lhes atribui ou reconhece. Quando o preconceito de raça se exerce em relação à aparência, isto é, quando toma por pretexto para as suas manifestações os traços físicos do indivíduo, a fisionomia, os gestos, o sotaque, diz-se que é de marca; quando basta a suposição de que o indivíduo descende de certo grupo étnico para que sofra as conseqüências do preconceito, diz-se que é de origem. (NOGUEIRA, 2006: 292).
\end{abstract}

Aqui, no Brasil, o preconceito racial se manifesta como preconceito de marca, sendo que a intensidade do preconceito varia de acordo com os traços negróides; não sendo incompatível com fortes laços de amizade ou incontestáveis manifestações de simpatia e solidariedade. Os traços negróides numa pessoa por quem se tem amizade ou simpatia, provocam pesar da mesma forma que uma deficiência física causariam. Desde cedo introjetam na mente da criança branca a noção de que as características negróides enfeiam e tornam o seu portador indesejável para o matrimônio. As crianças negras são pejorativamente chamadas de "negrinho(a)", "urubu”, "anu”, etc, tanto pelos colegas de brincadeiras como por adultos e outras crianças. Tem-se o hábito no Brasil de se dizer o seguinte gracejo "negro não é gente", e outras frases de mesmo impacto, sempre proferidas em tom de brincadeira, incutindo tanto na mente de crianças brancas como na de crianças negras a noção de "inferioridade" dos negros e a indesejabilidade das características negróides, mesmo que a pessoa que faça a brincadeira não tenha tomado consciência de sua ação e do efeito dela sobre os indivíduos.

Tem-se a esperança em nosso país que o negro e o índio desapareçam como tipos raciais, pela mestiçagem com o branco. $\mathrm{O}$ processo de branqueamento é visto como a forma mais apropriada para solucionar a questão da diversidade étnica brasileira. Quando uma pessoa branca se relaciona com uma pessoa negra, a impressão que se tem é que a negra teve "sorte" enquanto a branca teve "mau gosto" ou foi influenciada por motivos pouco confessáveis; se 
o casal tem filhos e os mesmos nascem com a pele clara é comum dizer que o casal foi "afortunado", se a criança nasce com a pele escura é vista com pesar. Mesmo que se combata ostensivamente o preconceito, a ideologia do branqueamento ou miscigenacionista se constitui como uma manifestação do mesmo, especialmente porque o indivíduo branco espera que o branqueamento seja realizado por outros brancos, e não por si mesmo, principalmente quando se trata do matrimônio (NOGUEIRA, 2006: 297).

O processo de embranquecimento ou branqueamento ocorre principalmente no campo sócio-cultural; na qual os negros absorvem valores culturais brancos tais como a língua, religião, vestes, etc. Mesmo os negros assumindo inicialmente os aspectos culturais ocidentais na tentativa de serem vistos em pé de igualdade com os brancos, continuavam sendo vistos como inferiores a estes. A recusa social se perpetuava, os intelectuais negros se dão conta que a única saída possível é a retomada de si, a negação do embranquecimento através da aceitação de sua herança sócio-cultural que deixava de ser considerada inferior. Essa retomada dos valores culturais africanos é chamada de negritude. Sem pretender cair num racismo às avessas. Como nos diz Munanga: "Tratava-se de uma reação. Legítima defesa ou racismo anti-racial, a negritude não deixa de ser uma resposta racial negra a uma agressão branca de mesmo teor”. (MUNANGA, 1988: 6).

A negritude é resultado da frustração dos intelectuais negros que não encontraram no humanismo ocidental a totalidade das dimensões de sua personalidade. Neste aspecto se configura como uma reação, uma defesa dos aspectos culturais negros. Configurando-se em protesto contra a postura europeia em querer ignorar outra realidade que não seja a sua, uma negação à assimilação colonial, rejeição política, um conjunto de valores negros que devem ser reencontrados, defendidos e até mesmo repensados.

No Brasil não houve uma tendência de utilizar o termo negritude para nomear todos os momentos da tomada de consciência do ser negro, a palavra passou a ser utilizada a partir da década de 1960, primeiramente por poetas e sempre com o sentido abrangente fazendo alusão à consciência e à reivindicação da comunidade negra. Dentre os vários momentos da tomada de consciência do ser negro no país, podemos destacar o surgimento do TEN (Teatro Experimental do Negro), em São Paulo em 1944, pois ele foi uma "espécie de 
modelo brasileiro da negritude”, pois defendia a recusa do negro a assimilação cultural e a recusa da miscigenação de maneira compulsória (BERND, 1988: 48).

Por meio do teatro e da imprensa foram sendo incorporadas ideias que possibilitaram os grupos negros refazerem seu referencial cultural, para ancorarem seu sentimento de identidade, dessa maneira o caminho estava sendo preparado para o surgimento das Associações de Negros Brasileiros na década de 1940. Outro fator importante foi a criação do Movimento Negro Unificado contra a Discriminação Racial (MNU) em 1978, que tem como um dos seus objetivos acabar com o mito da democracia racial e combater todas as formas de discriminação praticada contra os afrodescendentes.

A utilização do termo negritude gera muitas vezes polêmica, pois muitos intelectuais vêm como ultrapassado, sendo que o mesmo é definido como uma fase de conscientização da opressão colonialista, por se tratar de uma fase deve ser superada por outra. O movimento da negritude culminou com a busca, construção e consolidação de uma identidade negra positivada, "entendida como um processo dinâmico e não como um alvo estático a ser atingido" (BERND, 1988: 53).

Alguns idealizadores da negritude como Senghor, defenderam a crença em características inatas pertencentes ao grupo negro, essa postura abriu precedente para críticas violentas. Outro ponto que causa conflitos é a acusação por parte das elites dominantes de que o mesmo fomenta o conflito entre os grupos étnico-raciais na medida em que é visto como uma manifestação racista dos negros em relação aos brancos.

Diversos intelectuais como Cardoso, separam o pertencimento étnico da questão da negritude, por não concordarem com alguns aspectos assumidos pelo movimento: "Afro-descendência, ao contrário de negritude, não remete a uma identidade de natureza racialista e totalitária. Ela enfatiza a pluralidade de experiências da diáspora africana no tempo e no espaço".(2005: 173).

A necessidade de romper com as diversas manifestações de discriminação racial, levou muitos intelectuais a abandonarem o uso do termo raça, pelo mesmo estar associado à criação do "racismo científico" ancorado na ideia da existência de raças biologicamente superiores e inferiores, como está ideologia foi descartada pela biologia é comum que determinados intelectuais se 
oponham ao uso deste conceito, sendo o mesmo substituído pelo termo etnia.

A utilização deste visa enfatizar que os diversos grupos humanos não são marcados pelas características biológicas herdadas dos progenitores e ancestrais, mas sim por processos históricos e culturais. A etnia pode ser definida como:

Um grupo possuidor de algum grau de coerência e solidariedade, composto por pessoas conscientes, pelo menos em forma latente, de terem origens e interesses comuns. Um grupo étnico não é mero agrupamento de pessoas unidas ou proximamente relacionadas por experiências compartilhadas (CASHMORE Apud GOMES, 2005: 50).

As diferenças entre os seres humanos são construções culturais, políticas e sociais e não herdadas geneticamente, por isso, é importante estarmos atentos para o fato de que a nossa percepção do mundo ao nosso redor foi construída desde a infância de maneira a visualizar as diferenças e semelhanças de forma hierarquizada: beleza e feiúra, perfeições e imperfeições, etc. Quando esse pensamento é utilizado para se referir aos afrodescendentes, geralmente na questão da estética feminina, ocorre a reprodução do racismo e trabalhando-se com o conceito biológico de raça tão repudiado pela sociologia e antropologia.

É muito importante debatermos na sociedade, sobretudo na escola, a questão étnico/racial desmistificando o racismo para dessa maneira superarmos a discriminação racial. Ao contrário do que muita gente pensa, discutir publicamente o racismo não fomenta o conflito entre os diversos grupos étnico/raciais, pelo contrário, quando silenciamos este assunto é que reforçamos a existência da discriminação, do racismo e da desigualdade racial. Refletir sobre esse tema é algo que deve interessar toda a sociedade, e não apenas as pessoas que pertencem a este grupo étnico, é uma questão de toda a humanidade.

O conceito de etnia está vinculado ã questão da identidade, pois ela trata sobre o sentimento pertencimento do indivíduo a um determinado grupo, segundo Gomes:

A identidade não é algo inato. Ela se refere a um modo de ser no mundo e com os outros. É um fator importante na criação das redes de relações e de referências culturais dos grupos sociais. Indica traços culturais que se expressam através de praticas linguísticas, festivas, rituais, comportamentos alimentares e tradições populares referências civilizatórias que marcam a condição humana (2005: 41).

A identidade étnica é a utilização de termos raciais, nacionais ou religiosos para se identificar e se relacionar com outros (GLASSER apud OLIVEIRA, 
2003: 118). A formação de identidades étnicas em alguns casos se dá devido à segregação racial, no qual o mundo dos negros e o dos brancos é claramente separado, permitindo a formação de duas culturas independentes, uma branca e uma negra, incluindo religião e idioma, propiciando assim o surgimento de identidades étnicas. Já para Pereira a constituição da identidade étnica ocorre da seguinte maneira:

Se as reivindicações ligadas à classe encontram menor resistência, ou se diluem numa problemática geral da sociedade mais ampla, o mesmo não poderá ocorrer com relação àquelas decalcadas mais diretamente em questões de raça e de cultura que, em conjunto, compõem o que se convencionou a chamar de identidade étnica (PEREIRA: 1987).

Segundo Oliveira (2003: 120) a melhor maneira de darmos conta do processo de identificação étnica é elaborarmos o conceito de "identidade contrastiva”. Essa aparentemente constitui na essência da identidade étnica, a base da sua definição. Implicando a afirmação do nós diante dos outros. Quando um indivíduo ou um grupo se afirmam como tais, o fazem como mecanismo de diferenciação em relação a outro indivíduo ou grupo com que se defrontam, sendo uma identidade que surge por oposição, não se afirmando isoladamente. No caso da identidade étnica ela se afirma pela negação da outra identidade, vista por ela etnocentricamente. Nesse contexto o etnocentrismo, enquanto sistema de representação, é a afirmação empírica da emergência da identidade étnica no seu estado bruto ou "primitivo". Os mecanismos de identificação étnica podem estar sujeitos a princípios de estruturas comuns, tal não ocorre no contexto no qual estão inseridas as relações interétnicas, podendo estar sujeitas, esse contexto unifica naturalmente as estruturas de outra ordem.

Para encerrar, embora nosso currículo ainda contemple o ensino eurocentrista, a Lei 10.639/03 é um grande avanço para as escolas e a sociedade em geral. Mesmo levando em consideração algumas falhas presentes na Lei como nos aponta Santos:

\footnotetext{
Pensamos que o estabelecimento destas leis foi um avanço no processo de democratização do ensino, bem como na luta anti-racismo. [...] A legislação federal, segundo o nosso entendimento, é bem genérica e não se preocupa com a implementação adequada do ensino sobre História e Cultura Afro-Brasileira. Ela não estabelece metas para implementação da lei, não se refere à necessidade de qualificar os professore dos ensinos fundamental e médio para ministrarem as disciplinas referentes à Lei $\mathrm{n}^{0}$ 10.639/03, de 9 de janeiro de 2003, menos ainda, o que é grave segundo nosso entendimento, à necessidade de as universidades reformularem os seus programas de ensino e/ou cursos de graduação, especialmente os de licenciatura,
} 
para formarem professores aptos a ministrarem ensino sobre História e Cultura Afro-Brasileira. Ao que parece, a lei federal, indiretamente, joga a responsabilidade do ensino supracitado para os professores. Ou seja, vai depender da vontade e dos esforços destes para que o ensino sobre História e Cultura Afro-Brasileira seja ministrado em sala de aula. Essa lei também não indica qual é o órgão responsável pela implementação adequada da mesma, bem como, em certo sentido, limita o ensino da História e Cultura Afro-Brasileira às áreas de Educação Artística e de Literatura e História Brasileiras (SANTOS, 2005: 33).

Apesar das falhas presentes na Lei $\mathrm{n}^{0}$ 10.639/o3 se faz necessário que nós enquanto educadores(as) brancos(as) ou negros(as) cobramos junto ao Estado Brasileiro a aplicação efetiva da Lei, para que a mesma não venha a tornar-se letra morta. Pois, a partir do momento que a relação com o conhecimento não tiver como referência a valorização de uma cultura hegemônica, e que a diversidade passe a ser encarada como algo positivo para a relação social, estaremos caminhando para uma sociedade mais justa, tolerante e equânime.

\begin{abstract}
O educador como mediador do processo de transformação na escola deve atuar contra a exclusão e pela promoção da igualdade. Essa é a única forma, no nosso entendimento, de construir uma escola plural e democrática, e, fundamentalmente, trabalhar uma visão de educação voltada para a humanização. Ao olhar a escola, a sala de aula, o educador comprometido na Promoção da Igualdade Racial deverá "desarmar o espírito", buscar compreender a discriminação e os preconceitos embutidos na postura, linguagem e prática escolar; muitos deles construídos historicamente pela mentalidade escravista que permeia a sociedade. É necessário que os educadores assumam o compromisso com a perspectiva multicultural da educação. Ultrapassar os limites das ações pontuais para fazer com que o cotidiano das escolas as políticas educacionais de combate ao racismo façam parte da discussão sobre Reorientação Curricular, (re)construção do Projeto Político-Pedagógico e Formação Permanente dos Educadores (ROCHA, 2005: 203).
\end{abstract}

\title{
Bibliografia
}

ABREU, Martha e MATTOS, Hebe. Em torno das "Diretrizes curriculares nacionais para a educação das relações étnico-raciais e para o ensino de história e cultura afro-brasileira e africana": uma conversa com historiadores. Estudos Históricos. Rio de Janeiro, vol. 21, 2008, pp. 5-20.

ANDREWS, George Reid. Negros e brancos em São Paulo (1888-1988). Tradução: Magda Lopes. Bauru: EDUSC, 1991.

ARAUJO, Joel de e CARDOSO, Patricia de Resende. Alforria Curricular através da Lei 10.639. Revista Espaço Acadêmico, no ${ }^{\circ}$ 30, nov. de 2003. Disponível em: <htpp://www.espacoacademico.com.br/o3o/30caraujo.htm>. Acessado em Jul. 2009.

BERNARDINO, Joaze. Ação afirmativa e a rediscussão do mito da democracia racial no Brasil. Estudos afro-asiáticos [online], vol. 24, no 2, 2002, pp. 247273. 
BERND, Zilá. O que é negritude. São Paulo: Brasiliense, 1988.

BOTELHO, Denise. Lei $N^{0}$ 10.639/2003 e Educação Quilombola: inclusão educacional e população negra brasileira. SEED - Secretaria de Educação a distância. Educação Quilombola. Salto para o Futuro. Brasília: Ministério da Educação. Boletim 10, 2007, pp. 34-40.

BRASIL; Ministério da Educação e do Desporto; Secretaria de Educação Fundamental. Parâmetros curriculares nacionais: terceiro e quarto ciclos do ensino fundamental: história. Brasília: Secretária de Educação Fundamental, 1998.

CARDOSO, Paulino Francisco de Jesus. A vida na escola e a escola da vida: experiências educativas de afrodescendentes em Santa Catarina no século XX. IN: ROMÃO (2005, pp. 171-185).

CAVALLEIRO, Eliane dos Santos. Discriminação racial e pluralismo em escolas públicas da cidade de São Paulo. IN: SECAD (2005: 65-104).

DIAS, Lucimar Rosa. Quantos passos já foram dados? A questão de raça nas Leis Educacionais - da LDB de 1961 à Lei 10.639 de 2003. IN: ROMÃO (2005: 49-62).

DUTRA, Paulo Sérgio e CÁ, Lourenço Ocuni. A construção de identidades pela Lei 10.639/o3 nas escolas estaduais de Ji-Paraná-RO. Disponível em: <http://need.unemat.br/3_forum/artigos/1.pdf.> Acessado em Jul. 2009.

GARCIA, Hagrayzs Rosa e TAVARES, Danieli. Educação Quilombola: o caso de Furnas de Boa Sorte. Comunicação Oral. Cuiabá: UFMT, 2009. Disponível em: <http://www.ie.ufmt.br/semiedu2009/gts/gt2/ComunicacaoOral/HAGRAYZS \%20ROSA\%20GARCIA.pdf>, Acessado em Fev. de 2010.

GOMES, Nilma Lino. Alguns termos e conceitos presentes no debate sobre relações raciais no Brasil: uma breve discussão. IN: SECAD (2005: 39-62).

MARINHO Jr., Lenício Dutra. A Lei 10.639/o3 e seus reflexos na educação pública. Pontifícia Universidade Católica de Minas Gerais. 2008. Disponível em: $<$ http://www.simposioestadopoliticas.ufu.br/imagens/anais/pdf/CPo1.pdf.>. Acessado em Jul. 2009.

MOURA, Glória. Proposta Pedagógica: Educação Quilombola. IN: SEED (2007: 3-8).

MUNANGA, Kabengele. Uma abordagem conceitual das noções de raça, racismo, identidade e etnia. Palestra proferida no $3^{\mathrm{o}}$ Seminário Nacional Relações Raciais e Educação-PENESB-RJ, 05/11/o3.

. Negritude usos e sentidos. $2^{\text {a }}$ ed., São Paulo: Ática, 1988.

NOGUEIRA, João Carlos (coord.). Multiculturalismo e a pedagogia multirracial e popular. Florianópolis: Atilende, 2002.

NOGUEIRA, Oracy. Preconceito racial de marca e preconceito racial de origem: Sugestão de um quadro de referência para interpretação do material sobre relações raciais no Brasil. Tempo social, revista de sociologia da USP, vol. 19, $\mathrm{n}^{0}$ 1, 2006, pp. 287-308.

OLIVEIRA, Luiz Fernandes de. Concepções docentes sobre as relações étnicoraciais em educação e a Lei 10.639. Pontifícia Universidade Católica do Rio de 
Janeiro. 2007. Disponível em:

<http://www.anped.org.br/reunioes/30ra/trabalhos/GTo4-3068--Int.pdf.>

Acessado em Jul. 2009.

OLIVEIRA, Roberto Cardoso de. Identidade étnica, identificação e manipulação. Sociedade e Cultura. Goiânia: UFG, vol. 6, $\mathrm{n}^{\circ}$ 2, 2003, pp. 117-131.

PARÉ, Marilene Leal; OLIVEIRA, Luana Paré de e VELLOSO, Alessandra D' Aqui. A educação para quilombolas: experiências de São Miguel dos pretos em Restinga seca (RS) e da Comunidade Kalunga do Engenho II (GO). Cadernos Cedes. Campinas: UNICAMP, vol. 27, $\mathrm{n}^{\mathrm{O}}$ 72, 2007, pp. 215-232.

PEREIRA, João Baptista Borges. A criança negra: identidade étnica e socialização. Caderno de Pesquisa. São Paulo, no 63, 1987, pp. 41-45. Disponível em:

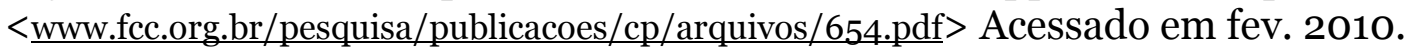

PEREIRA, Júnia Sales. Reconhecendo ou desconstruindo uma polaridade étnico-identitária? Desafios do ensino de história no imediato pós-Lei $\mathrm{n}^{\mathrm{o}}$ 10.639. Estudos Históricos. Rio de Janeiro, vol. 21, 2008, pp.21-43.

ROCHA, Lauro Cornélio. A formação de educadores(as) na perspectiva étnicoracial na rede municipal de ensino de São Paulo (2001-2004). IN: ROMÃO (2005: 201-218).

ROMÃO, Jeruse (org.). História da educação do negro e outras histórias. Coleção Educação para todos. Brasília: Ministério da Educação, Secretaria de Educação Continuada, Alfabetização e Diversidade. 2005.

SANTOS, Sales Augusto dos. A Lei $\mathrm{n}^{0}$ 10.639/03 como fruto da luta anti-racista do Movimento Negro. IN: SECAD (2005: 21-37. 2005).

SECAD - Secretaria de Educação Continuada, Alfabetização e Diversidade. Educação anti-racistas: caminhos abertos pela Lei Federal n ${ }^{0}$ 10.639/03. Coleção: Educação para todos. Brasília: Ministério da Educação, 2005.

SEED - Secretaria de Educação a distância. Educação Quilombola. Salto para o Futuro. Brasília: Ministério da Educação. Boletim 10, 2007.

SILVA, Lúcia Helena Oliveira. Ações afirmativas. Maquinações, vol. 1, 2007, pp. 74-76.

SILVA, Maria Dervania Vieira. Entre a luz e a sombra: a questão afro-brasileira e a Lei 10.639/o3 no contexto escolar. Umuarama-PR, 2009. Disponível em: <http://www.diaadiaeducacao.pr.gov.br/portals/pde/arquivos/2674.pdf?PHPS ESSID=2009050410452273. $>$ Acessado em Jul. 2009.

SILVA, Petronilha Beatriz Gonçalves e. Vamos acertar os passos? Referências afro brasileiras para os sistema de ensino. IN:

; LIMA, Ivan Costa e ROMÃO, Jeruse (orgs.). As Idéias Racistas, os Negros e a Educação. Florianópolis, Núcleo de Estudos Negros, 1997, pp. 39-56.

Colaboração recebida 28/02/2010 em e aprovada em 17/06/2010: 